\title{
Senescence, Apoptosis or Autophagy?
}

\author{
When a Damaged Cell Must Decide Its Path - A Mini-Review
}

\author{
José Miguel Vicencio ${ }^{\mathrm{a}-\mathrm{d}} \quad$ Lorenzo Galluzzi $^{\mathrm{a}-\mathrm{c}}$ Nicolas Tajeddine ${ }^{\mathrm{a}-\mathrm{c}}$ \\ Carla Ortiz ${ }^{a, c, d}$ Alfredo Criollo ${ }^{a-d}$ Ezgi Tasdemir ${ }^{a-c}$ Eugenia Morselli ${ }^{a-c}$ \\ Amena Ben Younes $^{a-c}$ Maria Chiara Maiuri ${ }^{a, b}$, e Sergio Lavandero ${ }^{d}$ \\ Guido Kroemer ${ }^{\mathrm{a}-\mathrm{c}}$ \\ aINSERM, U848, ${ }^{\mathrm{b}}$ Institut Gustave Roussy and ' Université Paris-Sud, Paris, France; ${ }^{\mathrm{d}}$ Universidad de Chile, \\ Facultades de Ciencias Químicas Farmacéuticas y de Medicina, Centro FONDAP Estudios Moleculares de la Célula,

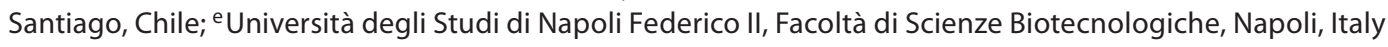

\section{Key Words}

Protein aggregates $\cdot$ Neurodegeneration $\cdot$ Caloric

restriction $\cdot \mathrm{p} 53 \cdot \mathrm{pRB}$

\begin{abstract}
Many features of aging result from the incapacity of cells to adapt to stress conditions. When damage accumulates irreversibly, mitotic cells from renewable tissues rely on either of two mechanisms to avoid replication. They can permanently arrest the cell cycle (cellular senescence) or trigger cell death programs. Apoptosis (self-killing) is the best-described form of programmed cell death, but autophagy (self-eating), which is a lysosomal degradation pathway essential for homeostasis, reportedly contributes to cell death as well. Unlike mitotic cells, postmitotic cells like neurons or cardiomyocytes cannot become senescent since they are already terminally differentiated. The fate of these cells entirely depends on their ability to cope with stress. Autophagy then operates as a major homeostatic mechanism to eliminate damaged organelles, long-lived or aberrant proteins and superfluous portions of the cytoplasm. In this mini-review, we
\end{abstract}

briefly summarize the molecular networks that allow damaged cells either to adapt to stress or to engage in programmed-cell-death pathways.

Copyright $\odot 2008$ S. Karger AG, Basel

\section{Introduction}

Unicellular and multicellular organisms live in a constant struggle to cope with extrinsic and intrinsic damaging agents. The inevitable accumulation of damage leads to the deterioration of cell components, impairment of cellular functions and alterations in tissue homeostasis that finally compromise the whole organism. Thus, aging is currently viewed as the natural decline in an organism's fitness over time [1], presumably as the result of accumulative and unrepaired damage. Many agerelated pathologies originate from limitations in the maintenance and repair mechanisms of DNA, or by anomalies in the antioxidant mechanisms that contribute to the detoxification of reactive oxygen species [2]. Oxidative damage plays a major role in oncogenesis and

\section{KARGER \\ Fax +4161306 1234 E-Mail karger@karger.ch} www.karger.com
(C) 2008 S. Karger AG, Basel 0304-324X/08/0542-0092\$24.50/0

Accessible online at: www.karger.com/ger
Dr. Guido Kroemer

INSERM U848, Institut Gustave Roussy, PR1

39 , rue Camille Desmoulins

FR-94805 Villejuif (France)

Tel. +33 1421160 46, Fax +33 1421166 55, E-Mail kroemer@igr.fr 
brain function decline, which is explained by age-associated increases in lipid peroxidation [3], protein oxidation [4] and oxidative modifications of genomic and mitochondrial DNA [5]. Despite the common origin of these illnesses, there are differences in the age at which they begin. The incidence of cancer increases dramatically after the age of 50, while the incidence of neurodegenerative disorders rises after the age of 70 . One important distinction between these two classes of pathologies is the type of cells that they affect. Cancer affects mitotic cells, while neurodegenerative disorders affect mainly postmitotic cells. So, the question arises of whether these cells are fundamentally distinct in their response to damaging agents.

According to the proliferative pattern of tissues, multicellular organisms can be divided into simple and complex [1]. After development and differentiation, simple organisms (e.g. Caenorhabditis elegans and Drosophila melanogaster) are composed solely of postmitotic cells, which are terminally differentiated and cannot replicate. Conversely, complex organisms (e.g. mammals) are composed of both postmitotic and mitotic cells, which are present in renewable tissues and maintain their potential to proliferate. One important difference between simple and complex organisms is the life span they achieve: the nematode $C$. elegans lives only a few weeks and the fruit fly $D$. melanogaster lives a few months, while mice can live a few years and humans many decades [2]. It is likely that the presence of renewable tissues gives organisms the ability to replace damaged cells, thereby increasing longevity. Nonetheless, the capacity of renewable tissues to regenerate themselves is associated with a deadly risk, i.e. cancer. Damage accumulation increases the risk of mitotic cells to acquire genomic DNA modifications and hence to become tumorigenic. In order to preserve the organism, damaged cells rely on two different mechanisms to halt their progression: they can either enter into permanent cell cycle arrest (a process known as cellular senescence) or trigger genetic cell death programmes to die silently, without affecting neighbour cells (by apoptosis and perhaps by autophagy).

For postmitotic cells however, the cell damage scenario is radically different. As their cell cycle is already arrested in phase $G_{0}$, they cannot become senescent. Without the advantage given by proliferative renewal, postmitotic cells such as neurons or cardiomyocytes are obliged to adapt to stress in order to ensure vital functions for the whole organism. In neurodegenerative pathologies such as Parkinson's, Alzheimer's or Hunting- ton's disease, protein aggregation is the consequence of an insufficient removal of oxidized, misfolded or aberrant proteins in the brain $[3,4,6,7]$. In this context, autophagy operates as the major pathway for the normal turnover of damaged elements [8]. In the next sections, we will summarize the molecular mechanisms that are involved in the processes of cellular senescence, apoptosis and autophagy.

\section{Cellular Senescence}

Cellular senescence refers to the arrest in the $G_{1}$ phase of the cell cycle of continuously proliferating cells, in response to stress that puts them at risk of malignant transformation [1]. Senescent cells adopt a flattened, enlarged morphology and exhibit specific molecular markers like senescence-associated $\beta$-galactosidase, senescence-associated heterochromatin foci and the accumulation of lipofuscin granules $[9,10]$. There are many stimuli conducive to cellular senescence. Among them, telomere shortening, DNA damage and oxidative stress are the best described $[1,2]$. In spite of the diversity of these stimulatory signals, they only converge onto two major effector pathways: the p53 pathway and the pRB pathway (fig. 1). In normal conditions, the tumour suppressor protein $\mathrm{p} 53$ is constitutively targeted to proteasome-mediated degradation by MDM2 (mouse double minute 2), but upon mitogenic stress or DNA damage, MDM2 activity is suppressed and functional p53 is able to activate the cyclindependent kinase inhibitor $\mathrm{p} 21$ which stops the cell cycle. In the second pathway, the retinoblastoma protein $\mathrm{pRB}$ is activated by p16 after cellular stress or DNA damage and then binds to members of the E2F family of transcription factors, known to regulate cell cycle progression [11, 12]. The two pathways manifest ample crosstalk in the control of cellular senescence, and can also overlap with death pathways $[13,14]$. One example is the observation that ventricular cardiomyocytes activate mitochondrial apoptosis when they are subjected to E2F to overexpression [15].

Even though cellular senescence is an adaptative response to stress that contributes to extending the life span of an organism, this phenomenon can have a negative impact on the organism's survival. With age, senescent cells accumulate in proliferative tissues and release various degradative proteases, growth factors and inflammatory cytokines that compromise the function of non-senescent neighbouring cells. After a massive accumulation of senescent cells, the proliferative capacity of 


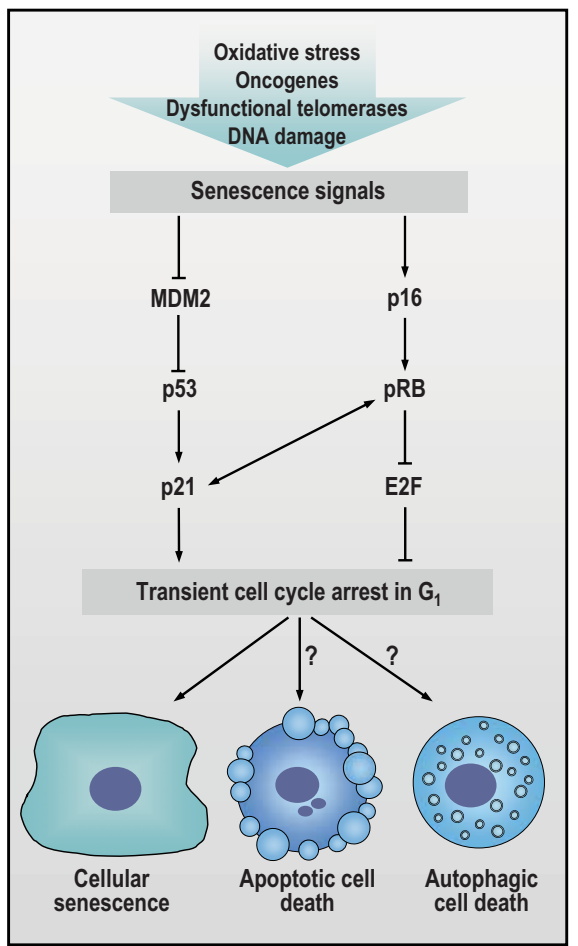

Fig. 1. p53 and pRB are the main tumour suppressor pathways. A simplified version of the complex molecular network involved in tumour suppression is shown for each pathway. p53 activates p21 which inhibits a series of cyclin-dependent kinases that control cell cycle progression. pRB inhibits E2F, a transcription factor required for the $G_{1}$ phase/S phase transition to cell cycle progression. After transient arrest in the $\mathrm{G}_{1}$ phase, unknown mechanisms result in either permanent cell cycle arrest (cellular senescence) or programmed cell death (apoptosis or autophagy).

renewable tissues diminishes because of a decrease in progenitor stem cells. Altogether, these effects may create a permissive environment that allows for the development of preneoplastic cells into tumours, counterbalancing longevity with the risk of old-age cancer $[1,2]$.

\section{Apoptosis}

Apoptosis is the best-described form of programmed cell death, and plays a major role in both embryonic development and organismal aging [16, 17]. It involves the controlled activation of proteases and other hydrolases that rapidly degrade all cellular structures. Unlike necrotic cell death, in which the cell membrane is disrupted and an inflammatory response is produced, apoptosis takes place within the borders of the intact plasma mem-

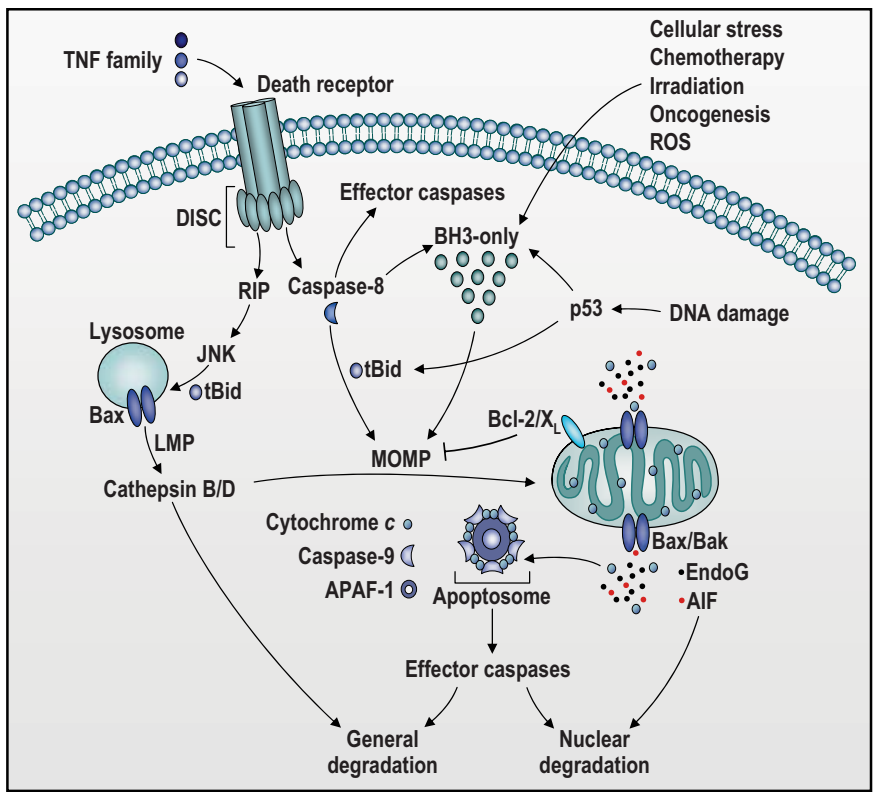

Fig. 2. Two major pathways lead to the execution of apoptosis. The extrinsic pathway is activated by the ligation of death receptors present in the plasma membrane. It propagates death signals in 3 directions: to lysosome membrane permeabilization (LMP), to caspase-8-dependent activation of effector caspases, or to $\mathrm{BH} 3$ only-dependent mitochondrial outer-membrane permeabilization (MOMP). The intrinsic pathway is stimulated by multiple signal transducers and noxious agents that frequently result in the activation of pro-apoptotic $\mathrm{BH} 3$-only proteins from the $\mathrm{Bcl}-2$ family. The rate-limiting step of the intrinsic pathway is mitochondrial membrane permeabilization resulting in the release of caspase activators and caspase-independent death effectors from mitochondria. AIF = Apoptosis-inducing factor; APAF-1 = apoptotic protease-activating factor 1 ; $\mathrm{Bak}=\mathrm{Bcl}-2$ antagonist killer; $\mathrm{Bax}=\mathrm{Bcl}$-2-associated $\mathrm{X}$ protein; $\mathrm{DISC}=$ death-inducing signaling complex; EndoG = endonuclease G; JNK = c-Jun N-terminal kinase; RIP = receptor-interacting protein 1 ; ROS $=$ reactive oxygen species; $\mathrm{tBid}=$ truncated $\mathrm{BH} 3$-interacting domain death agonist; TNF = tumour necrosis factor.

brane, without affecting neighbouring cells. At the morphological level, the classic hallmarks of apoptosis are the condensation of chromatin (pyknosis), nuclear fragmentation (karyorrhexis), shrinkage of the cell and plasma membrane blebbing [18]. Two major pathways initiate apoptosis: the intrinsic (or mitochondrial) and the extrinsic pathways (fig. 2).

In the intrinsic pathway [19], multiple sensors, including the $\mathrm{BH} 3$-only proteins and $\mathrm{p} 53$, react in response to different stress conditions or to DNA damage and activate a signaling cascade conducive to mitochondrial outer-membrane permeabilization (MOMP) [20]. The 


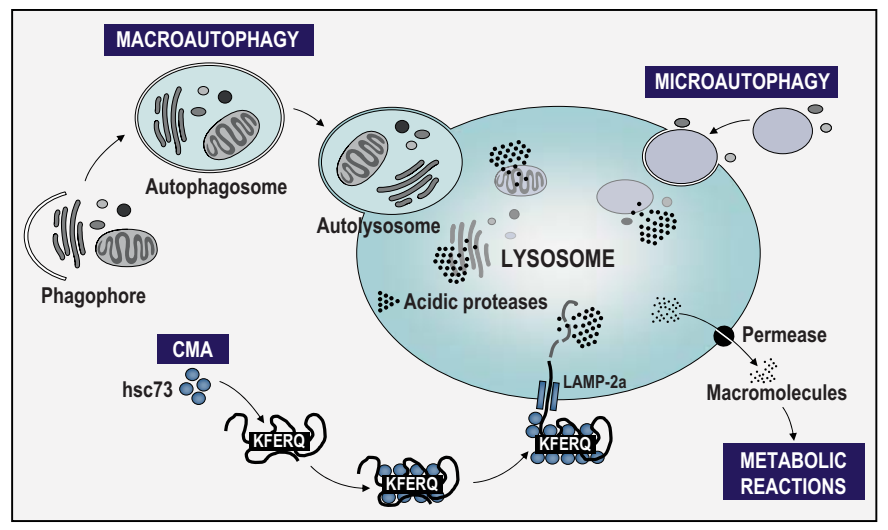

Fig. 3. Principal types and mechanisms of autophagy. CMA = Chaperone-mediated autophagy; hsc73 = heat shock 73-kDa protein; LAMP-2a = lysosomal-associated membrane protein type 2a.

release of intermembrane space proteins from permeabilized mitochondria allows for the assembly of the apoptosome, a caspase-activating complex formed by APAF-1 (apoptotic protease activating factor 1), caspase9 and cytochrome $c$, resulting in the activation of effector caspases that are responsible for dismantling the cell's structures [21]. Apoptosis initiated at the mitochondrial level is tightly regulated by the Bcl-2 family of proteins, which is subclassified into 3 groups: (1) anti-apoptotic multidomain members (Bcl-2, Bcl- $\mathrm{X}_{\mathrm{L}}$ and $\left.\mathrm{Mcl}-1\right)$, which contain four Bcl-2 homology domains (BH1, BH2, BH3 and BH4), (2) pro-apoptotic multidomain members (such as Bax and Bak), lacking the $\mathrm{BH} 4$ domain and (3) proapoptotic $\mathrm{BH} 3$-only proteins (such as Bid, Bim and Bad) [20]. Intrinsic and extrinsic stimuli can induce the proteolytic cleavage of Bid and translocation of truncated Bid (tBid) to the mitochondrial membranes where it stimulates MOMP, presumably through the activation of Bax/Bak channels and other mechanisms [22]. The multiple internal interactions among the $\mathrm{Bcl}-2$ protein family members, summed to the many pathways that modulate the levels and activity of these proteins, induce or avoid the execution of mitochondrial apoptosis [23].

The extrinsic pathway is initiated at the plasma membrane level by activation of death receptors from the TNFR (tumour necrosis factor receptor) family that include Fas/CD95 and the TRAIL (TNF-related apoptosisinducing ligand) receptors [24]. Ligand-induced death receptor trimerization results in the recruitment and activation of caspase- 8 via adaptor proteins such as FADD/ TRADD (Fas-associated death domain/TNFR1-associ- ated death domain) to form a death-inducing signalling complex, which further propagates death signals in at least 3 ways: (1) by direct proteolysis and activation of the effector caspases, (2) by proteolysis of the $\mathrm{BH} 3$-only protein Bid, translocation of $\mathrm{tBid}$ to mitochondria and consequent MOMP or (3) by activation of the kinases RIP1 (receptor-interacting protein 1) and JNK (c-Jun N-terminal kinase), that mediate the translocation of $\mathrm{tBid}$ to the lysosome and Bax-dependent lysosomal membrane permeabilization, resulting in cathepsin $\mathrm{B} / \mathrm{D}$-mediated general proteolysis and MOMP $[25,26]$.

\section{Apoptosis and Cellular Senescence}

Like cellular senescence, apoptosis is an extreme response to cellular stress and represents an important tumour-suppressive mechanism. It is still not clear what determines if a cell undergoes senescence or apoptosis. Although most cells are capable of both, these processes seem to be exclusive [1]. Cell type appears to be a determinant as damaged epithelial cells and fibroblasts tend to undergo senescence, while damaged lymphocytes tend to undergo apoptosis. Moreover, it has been reported that manipulations of the expression levels of Bcl-2 or caspase inhibition may cause cells that normally would have died by apoptosis to enter senescence [27,28]. Similarly, attempts to inhibit senescence by telomerase overexpression, do not prevent cellular senescence but rather protect cells from apoptosis $[29,30]$. These studies clearly point to a crosstalk between the processes of apoptosis and cellular senescence, for instance at the level of the tumour suppressor protein p53 [31]. In colon carcinoma cell lines, the activity of p53 has been shown to be balanced to the initiation of apoptosis rather than to the initiation of cellular senescence after oncogenic stress given by $c-m y c$ overexpression [32]. However, the cross-regulation between apoptosis and cellular senescence is far from understood and further studies are needed to clarify their relationship.

\section{Autophagy}

Autophagy (from the Greek words: 'auto' meaning self and 'phagein' meaning eating) is the process by which the cell's own components are delivered to lysosomes for bulk degradation (fig. 3). This ubiquitous process serves as the major turnover mechanism to eliminate damaged organelles, intracellular pathogens and superfluous portions of 
cytoplasm, as well as long-lived, aberrant or aggregated proteins. As a note, short-lived proteins are preferentially eliminated by the proteasome pathway. At least three different types of autophagy have been described, which differ in the mode of cargo delivery to lysosomes $[33,34]$. The most extensively described type is macroautophagy, in which portions of the cytosol and complete organelles are engulfed by double-membrane structures called autophagosomes or early autophagic vacuoles (AV-I). Upon fusion with the lysosome, autophagosomes form singlemembrane structures called autolysosomes or late autophagic vacuoles (AV-II) in which luminal content is degraded and resulting elements are returned into the cytosol for metabolic reactions. The regulation of autophagosome formation is complex (for an extensive review, see [35]). The major negative regulator of macroautophagy is the kinase mammalian target of rapamycin (mTOR), which normally allows baseline autophagosome formation, but its inhibition (i.e. by rapamycin or the absence of nutrients) triggers macroautophagy. mTOR inhibition is conducive to the enzymatic activation of a multiprotein complex formed by the class III phosphatidylinositol 3-kinase (PI3K) vacuolar protein sorting factor protein 34 (Vps34), Beclin 1, vacuolar protein sorting factor protein 15 (Vps15), UV radiation resistanceassociated gene (UVRAG), endophilin B1 (Bif-1), activating molecule in Beclin-1-regulated autophagy (Ambra 1) and perhaps other proteins. This complex is negatively regulated also by $\mathrm{Bcl}-2 / \mathrm{X}_{\mathrm{L}}[36,37]$. Vps 34 produces phosphatidylinositol-3-phosphate [PtdIns(3)P], a molecular signal for the recruitment of the autophagic effector machinery that allows vesicle elongation and closing [38]. Upstream of mTOR, macroautophagy can be inhibited by the insulin/IGF-1 (insulin-like growth factor 1) receptor pathway, where the class I PI3K product phosphatidylinositol-3,4,5-trisphosphate $\left[\operatorname{PtdIns}(3,4,5) \mathrm{P}_{3}\right]$ stimulates mTOR function [39].

Although it is not as well understood as macroautophagy, a second type of self-eating is microautophagy, in which the engulfment is made directly by the lysosomal membrane. This mechanism is also a degradation pathway for organelles and long-lived proteins, but, unlike macroautophagy, it is not responsible for the adaptation to nutrient deprivation. One particular form of microautophagy is the highly selective degradation of peroxisomes (micropexophagy), described in yeast as crucial for adapting to oxidative stress [40].

A third type of self-eating is chaperone-mediated autophagy (CMA). Although responsive to nutrient deprivation, this pathway exhibits no bulk engulfment by membranes and a selective recognition of substrates. In CMA, cytosolic proteins that contain a specific pentapeptide lysosome-targeting motif (consensus sequence KFERQ) are recognized by a complex of chaperone proteins (including heat shock $73-\mathrm{kDa}$ protein, hsc73) and targeted to the lysosomal membrane where they bind to the lysosome-associated membrane protein (LAMP) 2a. Substrate protein is then unfolded and transported into the lysosomal lumen for degradation [33]. A KFERQ-related motif is present in about $30 \%$ of cytosolic proteins, including RNase $\mathrm{A}$ and the amyloid $\beta$ precursor protein (APP) [41]. Interestingly, APP can be bound by hsc73 (and hence feed into CMA) when the default pathway for its degradation is inhibited, yet this interaction does not involve the APP KFFEQ sequence [42]. It is still not clear how the KFERQ-related motif is recognized by the chaperone complex. Some posttranscriptional modifications (e.g. oxidation, denaturation) of the substrates may render the motif more accessible to chaperones, increasing their lysosomal uptake by CMA.

\section{Autophagy and Apoptosis in Senescence}

In most circumstances, autophagy promotes cell survival by adapting cells to stress conditions. In this context it appears paradoxical that autophagy has also been considered as a non-apoptotic programme of cell death that is referred to as 'autophagic' or 'type-II' cell death. This is based on the finding that some cases of cell death are preceded or accompanied by massive autophagic vacuolization. However, these morphological observations cannot distinguish whether cell death is simply accompanied by the formation of autophagic vacuoles or whether cell death is truly executed by autophagy. In fact, the relationship between autophagy and apoptosis is complex, and exactly what determines if a cell dies by apoptosis or by other mechanisms is still elusive. In some cellular settings, autophagy is reportedly conducive to cell death when apoptosis is inhibited, acting as a backup mechanism to execute the death process [43]. In contrast, if during nutrient starvation the adaptative functions of autophagy are blocked, the result is accelerated death by apoptosis, which can be retarded by depleting Bax/Bak or inhibiting caspases [44]. In tumour cell lines exposed to cytotoxic drugs, autophagic cell death reportedly avoids apoptosis as well as cellular senescence [45, 46]. Again, the tumour suppressor protein $\mathrm{p} 53$ has been identified as a master regulator that guides the 'decisions' between these processes [11-13, 47-49]. 
In senescent and postmitotic cells, autophagy serves as a mechanism of adaptation to stress. In fact, autophagosomes have been shown to accumulate in senescent fibroblasts to facilitate the renewal of cytosolic compounds and organelles [50, 51]. Similarly in cardiomyocytes, optimal turnover of mitochondria depends on macroautophagy $[52,53]$. One type of autophagy - CMA - has been shown to decline with age, augmenting the risk of neurodegeneration associated with the accumulation of aggregate-prone mutant proteins [54-56]. It should be noted that age-associated neurodegenerative diseases share some characteristics with the pathology induced by knockout of autophagy-related (atg) genes in the brain, e.g. the accumulation of ubiquitinated proteins and inclusion bodies in the cytoplasm, an increase in apoptosis of neuronal cells and progressive neuronal cell loss [5759]. Whether this parallelism is mere conjecture or whether declining or insufficient autophagy truly contributes to the aging process awaits urgent clarification.

Nutrient starvation is the best-described inductor of autophagy in cultured cells, and autophagy is indeed the mechanism through which unicellular organisms (such as yeast cells) as well as mammalian cells can adapt to dwindling resources [60]. By degrading macromolecules, autophagy allows cells that lack an external nutrient supply to generate ATP and to survive. Importantly, this function of autophagy may also participate in the prolongation of the organism's life by caloric restriction. Fasting or dietary restriction is one of the strongest stimuli of autophagy in whole organisms including mice and the nematode C. elegans [61]. In a fascinating study, it has been shown that the deletion of atg genes abolished the antiaging effects of caloric restriction in C. elegans $[62,63]$. The exact mechanism through which autophagy reduces aging is elusive. However, it may be speculated that an enhanced turnover of cytoplasmic structures and molecules may 'clean' and hence rejuvenate cells. In addition, autophagy has a major role in maintaining genomic stability, through mechanisms that are not yet understood. Hence, an overall increase in autophagy might help to avoid the long-term effects of DNA damage [64], a hypothesis that requires further exploration.

\section{Summary and Concluding Remarks}

Embryogenesis and the development of multicellular organisms are the result of a balance between cell proliferation and cell death. After differentiation, tissues with proliferative cells and tissues with non-proliferative cells accumulate damage inherent to life and aging. In proliferative tissues, two different mechanisms have evolved to avoid the progression of damaged cells to cancer: proliferation arrest (a process known as cellular senescence) or programmed cell death (apoptosis and perhaps also massive autophagy). In addition, aging is associated with an ever-increasing risk of developing a different set of pathologies associated with cellular damage. In particular, neurodegeneration can develop because of a decline in the cellular mechanisms that operate to remove damaged elements. The major pathway for the degradation of cytoplasmic elements is autophagy, which reportedly declines with age. Inducing autophagy by caloric restriction may serve as a strategy to avoid the development of agerelated diseases, as this has been shown for C. elegans. However, it remains an open question whether the induction of autophagy (periodic or continuous) by caloric restriction (intermittent or constant) or pharmacological stimuli may have a beneficial effect on age-associated degenerative processes in humans.

\section{Acknowledgements}

G.K. is supported by a special grant from Ligue National contre le cancer (équipe labellisée), as well as by grants from Agence Nationale de Recherche, Agence Nationale pour la Recherche sur le Sida, Cancéropôle Ile-de-France, Fondation pour la Recherche Médicale, Institut National du Cancer, European Commission (ApoSys, RIGHT, Active p53, Trans-Death, Death-Train, ChemoRes) and Sidaction. G.K., S.L., J.M.V. and A.C. are supported by the international cooperation grant ECOS-CONICYT. J.M.V., C.O. and A.C. are recipients of doctoral fellowships from CONICYT, Chile. N.T. is recipient of a postdoctoral fellowship from Fondation pour la recherche médicale.

References

1 Campisi J, d'Adda di Fagagna F: Cellular senescence: when bad things happen to good cells. Nat Rev Mol Cell Biol 2007;8:729-740.

2 van Heemst D, den Reijer PM, Westendorp RG: Ageing or cancer: a review on the role of caretakers and gatekeepers. Eur J Cancer 2007;43:2144-2152.

-3 Bassett CN, Montine TJ: Lipoproteins and lipid peroxidation in Alzheimer's disease. J Nutr Health Aging 2003;7:24-29.

-4 Butterfield DA, Sultana R: Redox proteomics identification of oxidatively modified brain proteins in Alzheimer's disease and mild cognitive impairment: insights into the progression of this dementing disorder. J Alzheimers Dis 2007;12:61-72.

5 Hamilton ML, Van Remmen H, Drake JA, et al: Does oxidative damage to DNA increase with age? Proc Natl Acad Sci USA 2001;98: 10469-10474. 
6 Butterfield DA, Kanski J: Brain protein oxidation in age-related neurodegenerative disorders that are associated with aggregated proteins. Mech Ageing Dev 2001;122:945962.

$\checkmark 7$ Rojo L, Sjoberg MK, Hernandez P, et al: Roles of cholesterol and lipids in the etiopathogenesis of Alzheimer's disease. J Biomed Biotechnol 2006;1-17.

$\checkmark 8$ Williams A, Jahreiss L, Sarkar S, et al: Aggregate-prone proteins are cleared from the cytosol by autophagy: therapeutic implications. Curr Top Dev Biol 2006;76:89-101.

-9 Itahana K, Campisi J, Dimri GP: Methods to detect biomarkers of cellular senescence: the senescence-associated beta-galactosidase assay. Methods Mol Biol 2007;371:21-31.

-10 Kurz T, Terman A, Brunk UT: Autophagy, ageing and apoptosis: the role of oxidative stress and lysosomal iron. Arch Biochem Biophys 2007;462:220-230.

-11 Helmbold H, Deppert W, Bohn W: Regulation of cellular senescence by Rb2/p130. Oncogene 2006;25:5257-5262.

$>12$ Vaziri H, Benchimol S: Alternative pathways for the extension of cellular life span: inactivation of $\mathrm{p} 53 / \mathrm{pRb}$ and expression of telomerase. Oncogene 1999;18:7676-7680.

$\checkmark 13$ Kapic A, Helmbold H, Reimer R, et al: Cooperation between $\mathrm{p} 53$ and $\mathrm{p} 130(\mathrm{Rb} 2)$ in induction of cellular senescence. Cell Death Differ 2006;13:324-334.

-14 Maddika S, Ande SR, Panigrahi S, et al: Cell survival, cell death and cell cycle pathways are interconnected: implications for cancer therapy. Drug Resist Updat 2007;10:13-29.

15 Yurkova N, Shaw J, Blackie K, et al: The cell cycle factor E2F-1 activates Bnip3 and the intrinsic death pathway in ventricular myocytes. Circ Res 2007, E-pub ahead of print.

16 Kroemer G, Galluzzi L, Brenner C: Mitochondrial membrane permeabilization in cell death. Physiol Rev 2007;87:99-163.

17 Pollack M, Phaneuf S, Dirks A, et al: The role of apoptosis in the normal aging brain, skeletal muscle, and heart. Ann NY Acad Sci 2002;959:93-107.

-18 Galluzzi L, Maiuri MC, Vitale I, et al: Cell death modalities: classification and pathophysiological implications. Cell Death Differ 2007; 14:1237-1243.

-19 Kroemer G: Mitochondrial control of apoptosis: an introduction. Biochem Biophys Res Commun 2003;304:433-435.

20 Martinou JC, Green DR: Breaking the mitochondrial barrier. Nat Rev Mol Cell Biol 2001;2:63-67.

-21 Ferri KF, Kroemer G: Mitochondria - the suicide organelles. Bioessays 2001;23:111115.

-22 Zamzami N, El Hamel C, Maisse C, et al: Bid acts on the permeability transition pore complex to induce apoptosis. Oncogene 2000; 19:6342-6350.

-23 Green DR, Kroemer G: The pathophysiology of mitochondrial cell death. Science 2004; 305:626-629.
24 Choi C, Benveniste EN: Fas ligand/Fas system in the brain: regulator of immune and apoptotic responses. Brain Res Brain Res Rev 2004;44:65-81.

25 Dietrich N, Thastrup J, Holmberg C, et al: JNK2 mediates TNF-induced cell death in mouse embryonic fibroblasts via regulation of both caspase and cathepsin protease pathways. Cell Death Differ 2004;11:301-313.

26 Boya P, Andreau K, Poncet D, et al: Lysosomal membrane permeabilization induces cell death in a mitochondrion-dependent fashion. J Exp Med 2003;197:1323-1334.

27 Nelyudova A, Aksenov N, Pospelov V, et al: By blocking apoptosis, Bcl-2 in p38-dependent manner promotes cell cycle arrest and accelerated senescence after DNA damage and serum withdrawal. Cell Cycle 2007;6: 2171-2177.

28 Rebbaa A, Zheng X, Chou PM, et al: Caspase inhibition switches doxorubicin-induced apoptosis to senescence. Oncogene 2003;22 2805-2811.

29 Gorbunova V, Seluanov A, Pereira-Smith OM: Expression of human telomerase (hTERT) does not prevent stress-induced senescence in normal human fibroblasts but protects the cells from stress-induced apoptosis and necrosis. J Biol Chem 2002;277: 38540-38549.

30 Massard C, Zermati Y, Pauleau AL, et al: hTERT: a novel endogenous inhibitor of the mitochondrial cell death pathway. Oncogene 2006;25:4505-4514.

-31 Seluanov A, Gorbunova V, Falcovitz A, et al: Change of the death pathway in senescent human fibroblasts in response to DNA damage is caused by an inability to stabilize p53. Mol Cell Biol 2001;21:1552-1564.

32 Seoane J, Le HV, Massague J: Myc suppression of the p21(Cip1) Cdk inhibitor influences the outcome of the p53 response to DNA damage. Nature 2002;419:729-734.

33 Cuervo AM: Autophagy: many paths to the same end. Mol Cell Biochem 2004;263:5572.

34 Klionsky DJ, Cuervo AM, Dunn WA Jr, et al: How shall I eat thee? Autophagy 2007;3:413416.

35 Xie Z, Klionsky DJ: Autophagosome formation: core machinery and adaptations. Nat Cell Biol 2007;9:1102-1109.

36 Pattingre S, Tassa A, Qu X, et al: Bcl-2 antiapoptotic proteins inhibit Beclin 1-dependent autophagy. Cell 2005;122:927-939.

37 Maiuri MC, Le Toumelin G, Criollo A, et al: Functional and physical interaction between Bcl-X(L) and a BH3-like domain in Beclin-1. Embo J 2007;26:2527-2539.

38 Galluzzi L, Vicencio J, Kepp O, et al: To die or not to die: that is the autophagic question. Curr Mol Med 2008, in press.

39 Levine B, Kroemer G: Autophagy in the pathogenesis of disease. Cell 2008;132:2742 .
40 Farre JC, Subramani S: Peroxisome turnover by micropexophagy: an autophagy-related process. Trends Cell Biol 2004;14:515-523.

41 Dice JF, Terlecky SR: Targeting of cytosolic proteins to lysosomes for degradation. Crit Rev Ther Drug Carrier Syst 1990;7:211-233.

42 Kouchi Z, Sorimachi H, Suzuki K, et al: Proteasome inhibitors induce the association of Alzheimer's amyloid precursor protein with Hsc73. Biochem Biophys Res Commun 1999; 254:804-810.

43 Shimizu S, Kanaseki T, Mizushima N, et al: Role of Bcl-2 family proteins in a non-apoptotic programmed cell death dependent on autophagy genes. Nat Cell Biol 2004;6:12211228.

44 Maiuri MC, Zalckvar E, Kimchi A, et al: Selfeating and self-killing: crosstalk between autophagy and apoptosis. Nat Rev Mol Cell Biol 2007;8:741-752.

45 Demasters G, Di X, Newsham I, et al: Potentiation of radiation sensitivity in breast tumor cells by the vitamin D3 analogue, EB 1089, through promotion of autophagy and interference with proliferative recovery. Mol Cancer Ther 2006;5:2786-2797.

46 Hansen K, Wagner B, Hamel W, et al: Autophagic cell death induced by TrkA receptor activation in human glioblastoma cells. J Neurochem 2007;103:259-275.

47 Maclean KH, Dorsey FC, Cleveland JL, et al: Targeting lysosomal degradation induces p53-dependent cell death and prevents cancer in mouse models of lymphomagenesis. J Clin Invest 2008;118:79-88.

$\checkmark 48$ Reef S, Kimchi A: A smARF way to die: a novel short isoform of p19ARF is linked to autophagic cell death. Autophagy 2006;2: 328-330.

49 Zaidi AU, McDonough JS, Klocke BJ, et al: Chloroquine-induced neuronal cell death is p53 and Bcl-2 family-dependent but caspaseindependent. J Neuropathol Exp Neurol 2001;60:937-945.

50 Gerland LM, Peyrol S, Lallemand C, et al: Association of increased autophagic inclusions labeled for beta-galactosidase with fibroblastic aging. Exp Gerontol 2003;38:887895.

51 Stroikin Y, Dalen H, Brunk UT, et al: Testing the 'garbage' accumulation theory of ageing: mitotic activity protects cells from death induced by inhibition of autophagy. Biogerontology 2005;6:39-47.

52 Terman A, Dalen H, Eaton JW, et al: Mitochondrial recycling and aging of cardiac myocytes: the role of autophagocytosis. Exp Gerontol 2003;38:863-876.

$\checkmark 53$ Terman A, Brunk UT: The aging myocardium: roles of mitochondrial damage and lysosomal degradation. Heart Lung Circ 2005; 14:107-114.

54 Kaushik S, Cuervo AM: Autophagy as a cellrepair mechanism: activation of chaperonemediated autophagy during oxidative stress. Mol Aspects Med 2006;27:444-454. 
55 Kaushik S, Kiffin R, Cuervo AM: Chaperone-mediated autophagy and aging: a novel regulatory role of lipids revealed. Autophagy 2007;3:387-389.

56 Massey AC, Kiffin R, Cuervo AM: Autophagic defects in aging: looking for an 'emergency exit'? Cell Cycle 2006;5:1292-1296.

57 Nishiyama J, Miura E, Mizushima N, et al: Aberrant membranes and double-membrane structures accumulate in the axons of Atg5-null Purkinje cells before neuronal death. Autophagy 2007;3:591-596.
58 Hara T, Nakamura K, Matsui M, et al: Suppression of basal autophagy in neural cells causes neurodegenerative disease in mice. Nature 2006;441:885-889.

59 Komatsu M, Waguri S, Chiba T, et al: Loss of autophagy in the central nervous system causes neurodegeneration in mice. Nature 2006;441:880-884.

60 Lum JJ, Bauer DE, Kong M, et al: Growth factor regulation of autophagy and cell survival in the absence of apoptosis. Cell 2005;120: 237-248.

-61 Bergamini E, Cavallini G, Donati A, et al: The role of autophagy in aging: its essential part in the anti-aging mechanism of caloric restriction. Ann NY Acad Sci 2007;1114:6978
62 Morck C, Pilon M: Caloric restriction and autophagy in Caenorhabditis elegans. Autophagy 2007;3:51-53.

63 Bishop NA, Guarente L: Genetic links between diet and lifespan: shared mechanisms from yeast to humans. Nat Rev Genet 2007; 8:835-844.

64 Mathew R, Karantza-Wadsworth V, White E: Role of autophagy in cancer. Nat Rev Cancer 2007;7:961-967. 